\title{
INFLUÊNCIA DO REGIME PLUVIOMÉTRICO NO TRANSPORTE FLUVIAL DE SEDIMENTOS NA BACIA DO CÓRREGO MOEDA, TRÊS LAGOAS/MS
}

\author{
Rafael Brugnolli Medeiros ${ }^{1}$
}

\author{
André Luiz Pinto ${ }^{2}$
}

Luzilene de Oliveira Souza da Silva ${ }^{3}$

RESUMO: Este artigo avaliou a influencia do regime climático na vazão e no transporte de sedimentos em suspensão, ao longo das estações de inverno e primavera de 2011, e o verão de 2012, na bacia do Córrego Moeda. Bacia esta que, abrange $26.839,15$ ha no município de Três Lagoas e possui $55,7 \%$ de sua área recoberta por florestas de eucalipto e $19,9 \%$ com pastagens plantadas. Foram escolhidas onze estações de monitoramento ao longo do canal principal e da foz de seus afluentes da margem esquerda, os córregos Querência e Buriti. Concluiu-se que, após a forte estiagem do inverno, com penas 18,3 mm de precipitação, o solo ressecado e desagregado, ficou exposto às fortes chuvas da primavera, que promoveram elevado transporte de sedimentos em suspensão. No verão, apesar do pequeno acréscimo de precipitação em relação à primavera, ocorreu brusca redução do transporte, mostrando a eficiência das práticas conservacionistas, em especial, ao longo dos hortos 21 de eucalipto da FIBRIA MS celulose Sulmatogrossense Ltda. Concluiu-se que nesta bacia, o plantio de eucalipto, promove a infiltração, protegendo

\footnotetext{
1 Acadêmico do Curso de Geografia Bacharelado, da UFMS/CPTL - rafael_bmedeiros@hotmail.com;

2 Professor Doutor Associado II da UFMS/CPTL Departamento de Ciências Humanas andre.pinto@ufms.br;

3 Bolsista CAPES pelo Programa de Pós-graduação em Geografia da Universidade Federal de Mato Grosso do Sul - UFMS/CPTL - luzilene_souza@yahoo.com.br;
} 
mais o solo contra a ação das águas pluviais, proporcionando a redução do transporte de sedimentos em suspensão.

Palavras-chave: regime climático; vazão, transporte de sedimentos.

\section{INTRODUÇÃO}

O potencial do relevo exerce força sobre as águas fluviais, influenciando na sua velocidade, vazão e capacidade de dissecação, transporte e deposição de sedimentos. Hoje em dia surgem várias preocupações com o meio ambiente devido inúmeras modificações feitas na natureza.

Segundo TUCCI (2000), o Ciclo Hidrossedimentológico envolve o deslocamento, o transporte e o depósito de partículas sólidas presentes na superfície da bacia, sendo este intimamente ligado ao ciclo hidrológico. Canais fluviais são abastecidos pelo lento escoamento do lençol freático, sendo estes abastecidos por águas pluviais infiltradas no solo ou na rocha, ou diretamente pelo escoamento superficial das águas pluviais. Estas formas de escoamento podem ser vistas como meio de dissipação de energia da qual a água esta provida, ao se deslocar horizontalmente e verticalmente, sob ação da força gravitacional.

De acordo com Toy e Hadley (1987) apud Cunha (1997), a erosão dos solos é um processo "normal" no desenvolvimento da paisagem, sendo responsável pela remoção do material de superfície por meio do vento, do gelo ou da água. Sob tais condições, a erosão é considerada um processo natural. No entanto, a erosão acelerada dos solos, isto é, aquela que ocorre em intensidade superior à erosão "normal" é, usualmente, conseqüência dos resultados das atividades humanas sob determinadas condições de clima, vegetação, solo e relevo (VILELA FILHO, 2002).

Cunha (1997) quando o processo erosivo é mais intenso, sendo mais veloz que a formação do solo, ocorre à erosão acelerada - chamada de erosão antrópica - caso tenha sido provocada pela ação humana. 
Segundo Bertoni e Lombardo Neto (1990, p. 45), a chuva é um dos fatores de maior importância para a erosão, sendo que sua intensidade, sua duração e a sua freqüência são as propriedades mais importantes para o processo erosivo.

Poore e Fries (1985) afirmam que, quanto mais rápido o crescimento de uma árvore, maior seu consumo de água. Davidson (1993), entre outros estudos, aponta que, somente em áreas de precipitação pluviométrica inferior a $400 \mathrm{~mm} / \mathrm{ano}$, o eucalipto pode acarretar ressecamento do solo - ao utilizar as reservas de água nele contidas podendo, nesse caso, prejudicar também o crescimento de outras espécies.

Segundo Lal (1988, p. 142), vários pesquisadores têm usado índices baseados em medidas rotineiras das propriedades do solo para avaliar a sua relativa suscetibilidade à erosão, tendo sido criados vários índices, como medidas de desagregação do solo ou de sua resistência à desagregação.

Bertoni e Lombardo Neto (1990, p. 68), salienta que a erosão é o processo de desprendimento e arraste acelerado das partículas do solo, causado pela água e pelo vento. Que dependem do tipo de material a ser transportado, da energia potencial do relevo, da profundidade do lençol freático, entre outras variáveis naturais e antrópicas.

O regime climático disponibiliza no sistema fluvial, além do transporte decorrente da ação da água corrente, a diluição e assimilação dos contaminantes naturais e/ou introduzidos pelo manejo antrópico.

Cunha (1997) enfatiza que, quando o processo erosivo é mais intenso, sendo mais veloz que a formação do solo, ocorre à erosão acelerada - chamada de erosão antrópica caso tenha sido provocada pela ação humana.

A variação do potencial erosivo longo do ano, também é importante para o planejamento das práticas conservacionistas a serem implementadas nas bacias hidrográficas, principalmente para a estimativa das perdas de solo.

Para contribuir no entendimento da dinâmica fluvial das vazões e competência de transporte de sedimentos em suspensão na bacia do córrego Moeda, localizado no município de Três Lagoas/MS, perante as suas formas de uso, ocupação e manejo da terra, apresenta-se este estudo.

Para tanto monitorou-se estacionalmente a vazão e o transporte de sedimentos em suspensão, ao longo do inverno e primavera de 2011 e verão de 2012, e os correlacionou 
quantitativos pluviométricos, em 11 pontos de monitoramento, submetidos aos usos e manejos pecuários e de hortos de eucalipto,

Buscando avaliar a influencia do uso, ocupação e manejo da terra e do regime climático, na vazão e na competência de transporte fluvial, nas três estações do ano, na bacia.

\section{DESENVOLVIMENTO}

\subsection{METODOLOGIA}

Para a execução da mensuração da competência de transporte fluvial em suspensão, foram utilizados os seguintes softwares e equipamentos Word 2000; Excel 2007; Corel Draw 12 - Corel Photo-Paint 12 e Software Universal Desktop Ruler - UDR (mensurações areais). Em campo utilizou-se frascos plásticos de $500 \mathrm{ml}$, câmeras digitais fotográficas (registrar as condições atuais) e o Sistema de Posicionamento Global - GPS; Estufa de Secagem, Conjunto de infiltração, Bomba à Vácuo, Balança de Precisão e Membrana Filtrante - Milipores, 47 mícrons, em estér de celulose. Para a análise físicoquímica dos parâmetros acima apontados embasou-se nas metodologias descritas por CHRISTOFOLETTI (1980); PINTO (1985); PINTO et. al. (2009) e CARVALHO et. al. (2000).

A carga de sedimento em suspensão pelos cursos fluviais é obtida pela ação erosiva que as águas desempenham sobre a bacia de drenagem e o fundo dos leitos, especialmente.

Para a coleta nos onze pontos selecionados ao longo do canal principal do Córrego Moeda e na foz de seus principais afluentes, utilizou-se frascos plásticos de $500 \mathrm{ml}$, Figura 01 e Tabela 4. Os quais foram introduzidos nas áreas de maior velocidade do canal, até o fundo, sem que este se afunda no leito arenoso, para receber o fluxo de fundo com sedimentos em suspensão, ao longo das estações do inverno e primavera de 2011 e verão de 2012 (PINTO et. al., 2009).

Em laboratório os frascos foram agitados e colocados, $100 \mathrm{ml}$, em conjunto de infiltração da milipore, com filtro de 4,7 microns de celulose, que em seguida foram à 


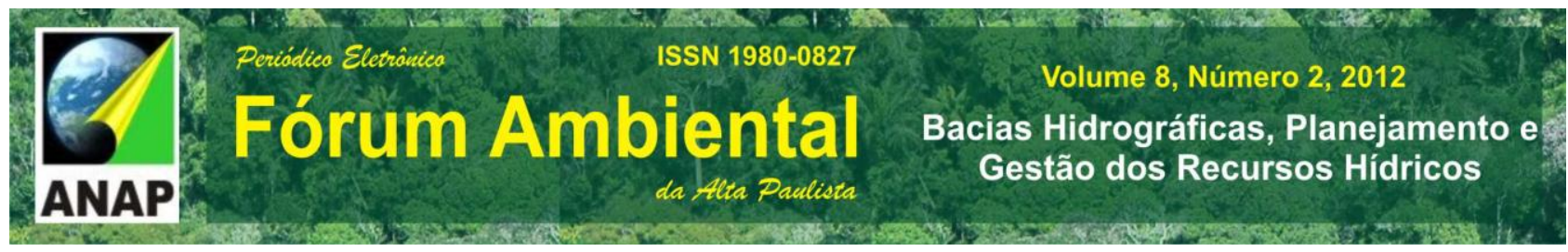

estufa de secagem por 24 horas a $60^{\circ} \mathrm{C}$. Logo após resfriarem os filtros foram pesados em balança de precisão e compará-los com o peso de seus respectivos filtros sem sedimentos, como os valores correspondem a $100 \mathrm{ml}$, estes foram convertidos para $\mathrm{m}^{3} \mathrm{e}$ calculados os valores conforme as vazões mensuradas.

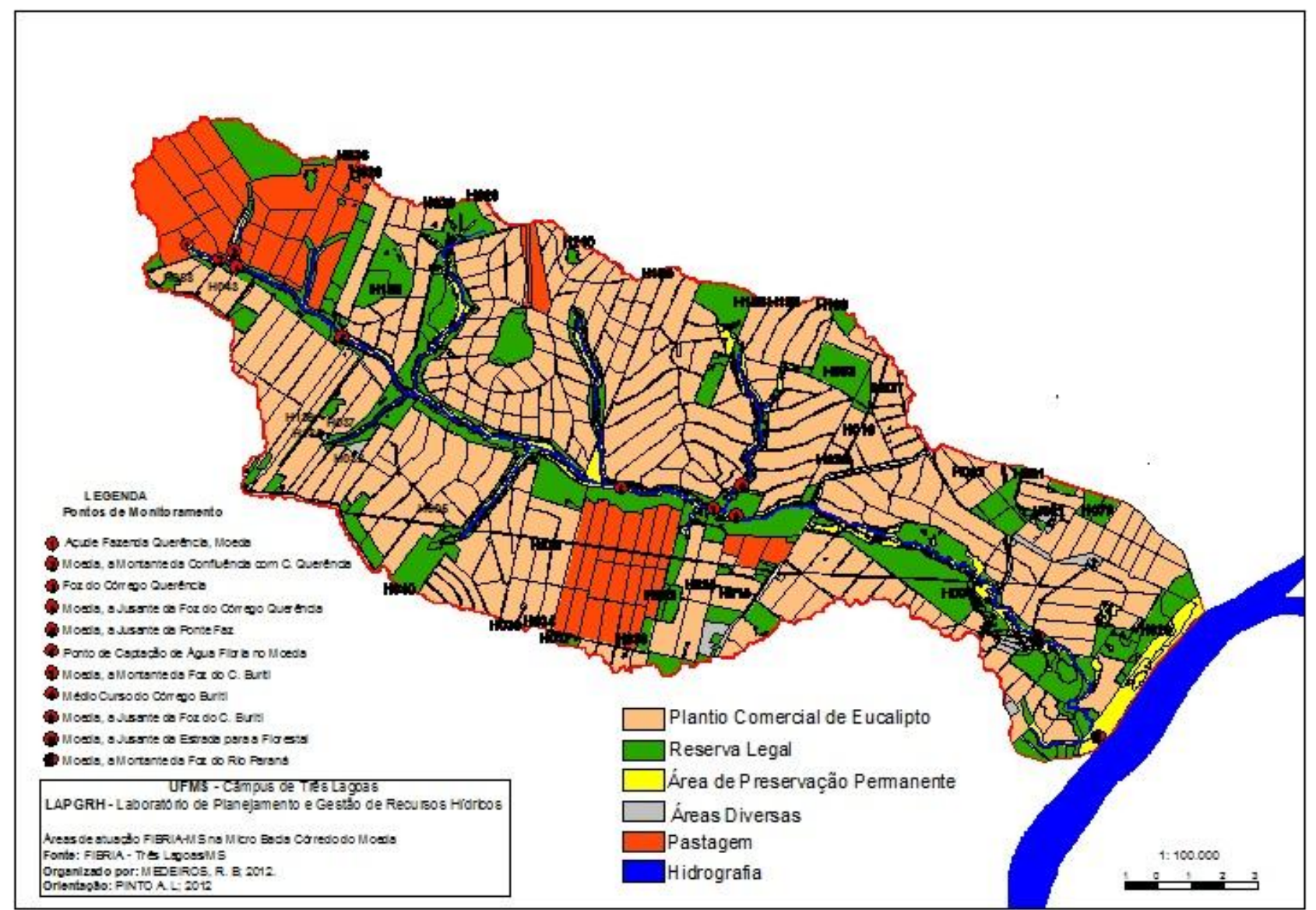

Figura 01: Localização dos Talhões de Eucalipto e Pontos de Monitoramento da Vazão e da Competência de Transporte de Sedimentos em Suspensão na Bacia do Córrego Moeda, Três Lagoas/MS.

Tabela 04: Localização das estações de monitoramento na bacia do córrego Moeda, Três Lagoas/MS, Brasil.

\begin{tabular}{l|l|l|l}
\hline $\begin{array}{l}\text { Estações } \\
\text { Coleta }\end{array}$ & $\begin{array}{l}\text { Coordenadas } \\
\text { Geográficas }\end{array}$ & Localização na Bacia & Ponto de Referência \\
\hline 1 & $\begin{array}{l}20^{\circ} 52^{\prime} 139^{\prime \prime} \text { S } \\
51^{\circ} 59^{`} 577^{\prime \prime} \text { W }\end{array}$ & Alto Curso do Córrego Moeda. & Açude na Fazenda Querência \\
\hline 2 & $\begin{array}{l}20^{\circ} 52^{\prime} 435^{\prime \prime} \text { S } \\
51^{\circ} 59^{\prime} 325^{\prime \prime} \text { W }\end{array}$ & $\begin{array}{l}\text { Alto Curso do C. moeda, a montante da } \\
\text { foz do Querência. }\end{array}$ & Fazenda Querência \\
\hline
\end{tabular}

VIII Fórum Ambiental da Alta Paulista, v. 8, n.2, 2012, p. 30-48. 


\begin{tabular}{|c|c|c|c|}
\hline 3 & $\begin{array}{l}20^{\circ} 52 ' 266^{\prime \prime} \mathrm{S} \\
5159^{\prime} 211^{\prime \prime} \mathrm{W}\end{array}$ & Foz do C. Querência no C. Moeda. & Fazenda Querência \\
\hline 4 & $\begin{array}{l}20^{\circ} 52^{\prime} 271 \mathrm{~S} \\
51^{\circ} 59^{\prime} 211 \mathrm{~W}\end{array}$ & $\begin{array}{l}\text { Alto Curso do C. Moeda, a jusante da foz } \\
\text { do C. Querência. }\end{array}$ & Fazenda Querência \\
\hline 5 & $\begin{array}{l}20^{\circ} 53^{\prime} 509^{\prime \prime} \mathrm{S} \\
51^{\circ} 57^{\prime} 637^{\prime \prime} \mathrm{W}\end{array}$ & $\begin{array}{l}\text { Médio Curso do C. Moeda, a jusante da } \\
\text { ponte. }\end{array}$ & Ponte. Horto Granada, Fíbria \\
\hline 6 & $\begin{array}{l}20^{\circ} 55^{\prime} 780^{\prime \prime} \mathrm{S} \\
51^{\circ} 53^{\prime} 270^{\prime \prime} \mathrm{W}\end{array}$ & Médio Curso do C. Moeda. & $\begin{array}{l}\text { Clareira aberta para coleta } \\
\text { d'água para molha do eucalipto } \\
\text { e incêndio. Horto Buriti, Fibria. }\end{array}$ \\
\hline 7 & $\begin{array}{l}20^{\circ} 56^{\prime} 481^{\prime \prime} \mathrm{S} \\
51^{\circ} 51^{\prime} 430^{\prime \prime} \mathrm{W}\end{array}$ & $\begin{array}{l}\text { Médio do C. Moeda, à montante do C. } \\
\text { Buriti }\end{array}$ & Horto do Buriti, Fibria. \\
\hline 8 & $\begin{array}{l}20^{\circ} 56^{\prime} 148^{\prime \prime} \mathrm{S} \\
51^{\circ} 50^{\prime} 996 " \mathrm{~W}\end{array}$ & Foz do C. Biriti no Médio do C. Moeda. & Horto do Buriti, Fibria. \\
\hline 9 & $\begin{array}{l}20^{\circ} 56^{\prime} 522 " \mathrm{~S} \\
51^{\circ} 51^{\prime} 287^{\prime \prime} \mathrm{W}\end{array}$ & $\begin{array}{l}\text { Médio do Córrego Moeda, á jusante da foz } \\
\text { do Córrego Buriti. }\end{array}$ & Horto do Buriti, Fibria. \\
\hline 10 & $\begin{array}{l}20^{\circ} 58^{\prime} 525^{\prime \prime} \mathrm{S} \\
51^{\circ} 46^{\prime} 242^{\prime \prime} \mathrm{W}\end{array}$ & Baixo Curso do Córrego Moeda. & $\begin{array}{l}\text { Clareira aberta para coleta } \\
\text { d'água para molha do eucalipto } \\
\text { e incêndio. Horto Dobrão, } \\
\text { Fibria. }\end{array}$ \\
\hline 11 & & Baixo Curso do Córrego Moeda. & $\begin{array}{l}\text { Foz do Córrego Moeda do Rio } \\
\text { Paraná. Horto Dobrão, Fibria. }\end{array}$ \\
\hline
\end{tabular}

A vazão foi utilizada as técnicas propostas por Pinto e Mauro (1985), para mensuração da área da seção do canal e a velocidade empregando o medidor de fluxo da Global Water F101.

Os dados pluviométricos foram obtidos do Inemet de 1931 a 1990 e da Fibria MS celulose Sul-matogrossense Ltda de 1990 até março de 2012.

\subsection{RESULTADOS E DISCUSSÃO}

O Córrego Moeda drena uma área de 26.839,15 ha, que em abril de 2012, possuía $14.934,10$ ha ocupados com florestas de eucalipto, totalizando 55,7\%, a pecuária extensiva de corte ocupa $19,9 \%$ e as APPs e reservas legais $24,4 \%$.

O reflorestamento ou plantio comercial de espécies arbóreas é a atividade agrícola que mais se recomendada para a conservação do solo, proteção dos mananciais e a 
recuperação de áreas degradadas. Precisamente, por este motivo, é que se considera a silvicultura e os cultivos perenes como os mais indicados sistemas de uso da terra para regimes de clima tropical, onde são mais graves os riscos de degradação do solo através da erosão e lixiviação. Como bem mostra a Tabela 1, pois enquadra-se o eucalipto na categoria de mata, ainda com as vantagens da espécie plantada na bacia a E.urograndis,que constitui cruzamento e modificação das espécies Eucalyptus grandis e Eucalyptus urophylla, que possui, boa copa e raízes com comprimento médio de 1,30 m a $1,50 \mathrm{~m}$, no ponto de corte aos seis anos. Enquanto que a grande maioria das espécies de mata nativa ultrapassam 3,0 m (VITAL, 2007).

Tabela 1- Perdas por Erosão em Função do Uso do Solo

\begin{tabular}{|c|c|c|c|}
\hline \multicolumn{4}{|c|}{ Perdas por Erosão em Função do Uso do Solo } \\
\hline \multirow[b]{2}{*}{ Uso do solo } & \multicolumn{2}{|c|}{ Perda por Erosão } & \multirow{2}{*}{$\begin{array}{l}\text { Tempo (anos) para } \\
\text { de desgaste de uma camada } \\
\text { de } 15 \mathrm{~cm} \text { de solo }\end{array}$} \\
\hline & Terra (t/ha) & $\begin{array}{l}\text { Agua }(\% \\
\text { chuva) }\end{array}$ & \\
\hline Mata & 0,0004 & 0,7 & 440.000 \\
\hline Pastagem & 0,4 & 0,7 & 4.000 \\
\hline Cafezal & 0,9 & 1,1 & 2.000 \\
\hline Algodoal & 26,6 & 7,2 & 70 \\
\hline
\end{tabular}

Se, por um lado, o consumo absoluto de água pelo eucalipto encontra-se, de fato, entre os mais altos, Figura 2, devido seu rápido crescimento, já o consumo relativo dessa água é baixo, Tabela 3 . 
Tabela 2 Consumo de Água por Diferentes Culturas

\begin{tabular}{c|c}
\hline CULTURA & $\begin{array}{c}\text { CONSUMO DE ÁGUAANO } \\
(\mathbf{m m})\end{array}$ \\
\hline Cana-de-Açúcar & $100-2.000$ \\
\hline Café & $800-1.200$ \\
\hline Citrus & $600-1.200$ \\
\hline Milho & $400-800$ \\
\hline Feijão & $300-600$ \\
\hline Eucalipto & $800-1.200$ \\
\hline
\end{tabular}

Fonte: Ipef (2003).

Para o IPEF (2003) além de proteger mais o solo o eucalipto possui alta eficiência no consumo da água, enquanto que o cerrado necessita 2.500 litros de água por kilograma, o eucalipto precisa de apenas $350 \mathrm{l} / \mathrm{kg}$, Tabela 3.

Tabela 3- Eficiência no Uso da Água em Diversas Culturas

\begin{tabular}{c|c}
\hline CULTURA & $\begin{array}{c}\text { EFICIÉNCIA NO USO DA } \\
\text { ÁGUA }(\mathbf{l} / \mathbf{k g})\end{array}$ \\
\hline Batata & 2.000 \\
\hline Milho & 1.000 \\
\hline Cana de Açúcar & 500 \\
\hline Cerrado & 2.500 \\
\hline Eucalipto & 350 \\
\hline
\end{tabular}

Fonte: Ipef (2003).

$\mathrm{Na}$ bacia predominam relevo suavemente aplainado, recobertos por latossolos vermelho amarelo, com textura media, que se assenta sobre terrenos do grupo Bauru, formação Santo Anastácio. Tendo assim as matas ciliares encontra-se em sua grande maioria em estagio de regeneração, com exceção de manchas dispersas sobre tudo no 
alto curso na margem esquerda, fazenda Querência e no baixo curso, área da FIBRIA MS celulose Sul-matogrossense Ltda. Devido a isso, deve-se reconhecer que são os fatores hidrológicos que controlam as características e o regime dos cursos de água.

Christofoletti (1981) salienta que o modo de utilização realizada nas áreas drenadas pela bacia hidrográfica repercute diretamente na composição química das águas, sendo que os dejetos, detritos e poluentes lançados pelas áreas urbanas e industriais causam modificações acentuadas na concentração de matéria dissolvida, repercutindo no balanço biológico das águas, nos processos de corrosão e nos de sedimentação.

Segundo Christofoletti (1980), os fatores hidrológicos, cujos mais importantes são a quantidade da cobertura vegetal influenciam a formação do material intemperizado na bacia hidrográfica e o carregamento desses materiais até os rios. O fluxo e o transporte de sedimentos constituem respostas aos processos e ao estado de equilíbrio atuante no sistema fluvial.

O Histograma mostra o comportamento termopluviométrico da bacia, segundo as normais, sendo a maneira simples de compara-se as variações climáticas mensais. Geralmente utiliza-se normais climáticas, para o presente trabalho, utilizou-se os dados de 1961 a 2011, pois constitui-se série histórica sem interrupção de dados, portanto constitui-se base confiável para estabelecimento de um padrão de comportamento climático. Com o climograma pode-se identificar os períodos úmidos e secos de um determinado local.

Pode-se classificar uma localidade, segundo diversos critérios, como tipo climático, como exemplo Koppen, o qual classifica a área de estudo como Aw, tropical com verão chuvoso e inverno seco, ou pela identificação de períodos super úmidos, e secos, conforme histograma (Figura 2).

A precipitação media anual considerando os dados do Inemet de 1931 a 1990 e da Fibria de 1990 até março de 2012, registram 1.321,50 mm. 

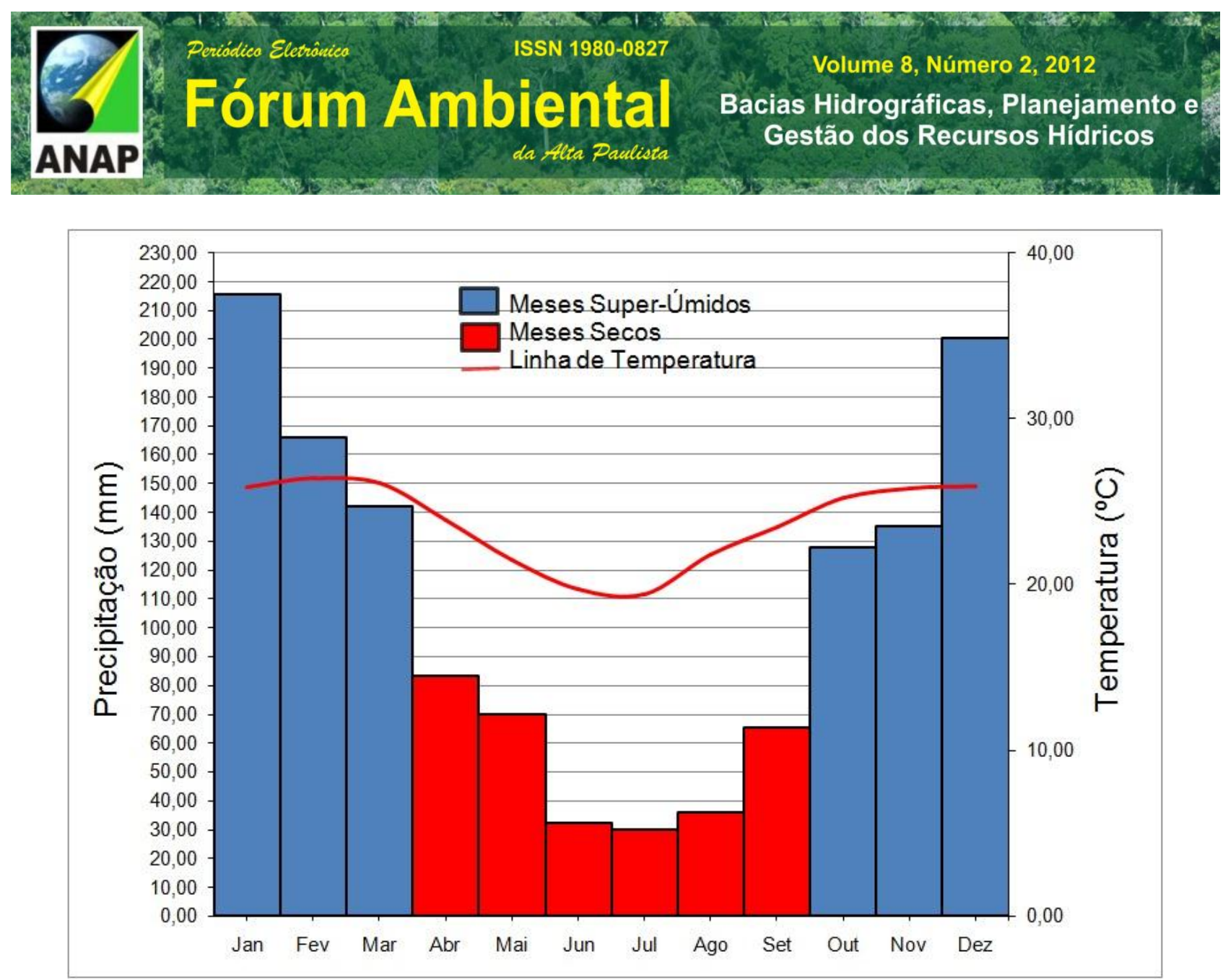

Figura 2 - Histograma da Bacia do Córrego Moeda, Três Lagoas/MS.

Org: R. B. Medeiros (2012).

Analisando o climograma da microbacia do Córrego Moeda nota-se a ausência de período úmido, pois nos meses de Janeiro, Fevereiro, Março, Outubro, Novembro e Dezembro verificaram-se precipitações superiores a $100 \mathrm{~mm}$. Os demais meses registraram precipitações abaixo dos $100 \mathrm{~mm}$ caracterizando como meses secos.

A bacia possui 6 meses super úmidos e 6 meses secos. $O$ período chuvoso estende-se de Outubro a Março abrangendo, sobretudo a primavera e o verão. A estação mais fria e mais seca é o inverno onde as precipitações ficam abaixo dos $60 \mathrm{~mm}$.

No outono (Abr., Mai. e Jun.), ocorrem 3 meses secos, não sendo muito perceptível na paisagem, pois o mês de Abril vem de uma sequência de meses super úmidos.

Nota-se, portanto que o verão e a primavera, juntos somam em torno de $80 \%$ de toda a precipitação que ocorre na bacia, mesmo com o equilíbrio de meses super úmidos e meses quentes, com esse excesso hídrico e expressivo escoamento superficial, consecutivo elevado potencial erosivo, conforme modelo proposto por Bertoni e Lombardi Neto (1999) e de competência de transporte fluvial Pinto (1985). 


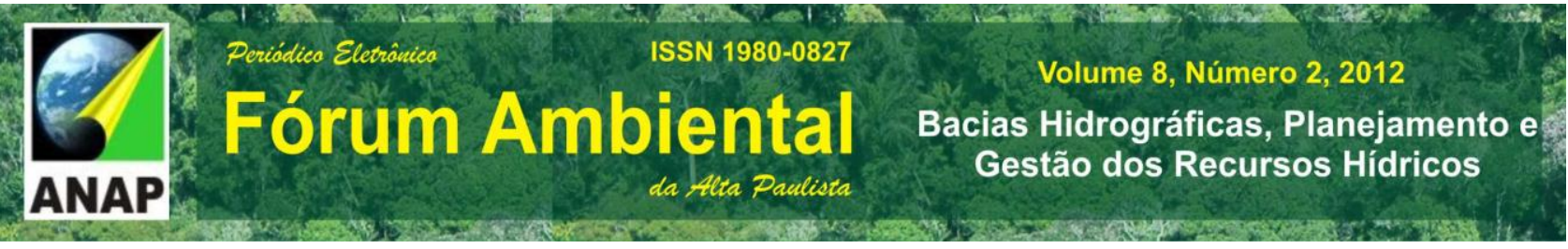

Em 2011, o total de precipitação somou $1.321,0 \mathrm{~mm}$, apenas $30,5 \mathrm{~mm}$ acima da media anual, o inverno mensurou-se somente $18,3 \mathrm{~mm}$, bem abaixo da media da estação que é de 112,1 mm A primavera, com 437,8 mm, posicionou-se também abaixo da media, desta estação, que é de $458,5 \mathrm{~mm}$ e o verão pouco chuvoso de 2012, somou $386,09 \mathrm{~mm}$, enquanto que a normal é de $602,1 \mathrm{~mm}$.

Com base nas mensurações mensais de velocidade, área e de transporte de sedimentos fluviais em suspensão, durantes as estações analisadas, nas onze estações de coleta, contudo os pontos 1 , localizado no alto curso, a atual nascente do córrego Moeda posiciona-se em um açude. E ponto 11, na voz com o rio Paraná, que por receber o refluxo das águas do Paraná represado pela usina de Rosana, forma grande alagamento, por esta razão e ambos os pontos não foram mensuradas as vazões (Tabelas 5, 6 e 7).

Tabela 5: Mensurações de velocidade, área e de transporte de sedimentos fluviais em suspensão coletados no Inverno de 2011, no córrego Moeda, Três Lagoas/MS.

INVERNO de 2011

\begin{tabular}{|c|c|c|c|c|c|c|c|}
\hline \multirow[b]{2}{*}{ Pontos } & \multirow{2}{*}{$\begin{array}{l}\text { Velocidade } \\
\text { (m/s) }\end{array}$} & \multirow{2}{*}{$\begin{array}{l}\text { Area } \\
\left(\mathrm{m}^{2}\right)\end{array}$} & \multirow{2}{*}{$\begin{array}{l}\text { Vazão } \\
\left(\mathrm{m}^{3} / \mathrm{s}\right)\end{array}$} & \multicolumn{4}{|c|}{ Competência Fluvial } \\
\hline & & & & $\begin{array}{c}\mathrm{g} / 100 \\
\mathrm{ml}\end{array}$ & $\mathrm{g} / \mathrm{m}^{3}$ & $\mathrm{~g} / \mathrm{m}^{3} / \mathrm{s}$ & Ton/Estação \\
\hline 1 & 0,2 & & -- & 0,0085 & 85,0000 & -- & -- \\
\hline 2 & 1,1 & 0,01228 & 0,01351 & 0,0005 & 5,0000 & 0,06754 & 0,53 \\
\hline 3 & 1,45 & 0,00675 & 0,00979 & 0,0005 & 5,0000 & 0,04894 & 0,38 \\
\hline 4 & 1,4 & 0,01469 & 0,02057 & 0,0011 & 11,0000 & 0,22623 & 1,76 \\
\hline 5 & 6,9 & 0,03330 & 0,22977 & 0,0004 & 4,0000 & 0,91908 & 7,15 \\
\hline 6 & 4,2 & 0,06958 & 0,36182 & 0,0008 & 8,0000 & 2,33789 & 18,18 \\
\hline 7 & 11,62 & 0,26744 & 3,10765 & 0,0006 & 6,0000 & 18,64592 & 145,00 \\
\hline 8 & 0,4 & 0,02127 & 0,00851 & 0,0012 & 12,0000 & 0,10210 & 0,79 \\
\hline 9 & 6,9 & 0,16760 & 1,15644 & 0,0009 & 9,0000 & 10,40796 & 80,93 \\
\hline 10 & 12,6 & 0,11823 & 1,48970 & 0,0003 & 3,0000 & 4,46909 & 34,75 \\
\hline 11 & 0,4 & -- & -- & 0,0005 & 5,0000 & -- & -- \\
\hline TOTAL & -- & -- & -- & 0,0153 & 153,0000 & 34,88685 & 289,46 \\
\hline
\end{tabular}


Durante o Inverno de 2011, observa-se que o ponto 7, localizado a montante da foz do córrego Buriti, como sendo o de maior competência de transporte em suspensão, entre todos os pontos monitorados, remontando em $53,45 \%$ do total transportado ao longo da bacia. Devido à existência na margem direita do canal, neste ponto, ser ocupado por antigo bebedouro para gado e seu uso predominante ser de pastagens, sem curvas de nível, Tabela 5 e Figura 3.

Percebe-se ainda, que o grau do transporte de sedimentos em relação às outras estações (Tabelas 6 e 7), é muito baixo, devido a pouca precipitação na área durante esse período.

Tabela 6: Mensurações de velocidade, área e de transporte de sedimentos fluviais em suspensão na Primavera de 2011, no córrego Moeda, Três Lagoas/MS.

\section{PRIMAVERA de 2011}

\begin{tabular}{c|c|c|c|c|c|c|c}
\hline \multirow{2}{*}{ Pontos } & Velocidade & Área & Vazão & \multicolumn{4}{|c}{ Competência Fluvial } \\
\cline { 5 - 8 } & $(\mathbf{m} / \mathbf{s})$ & $\left(\mathbf{m}^{2}\right)$ & $\left(\mathbf{m}^{\mathbf{3} / \mathbf{s})}\right.$ & $\mathbf{g} / \mathbf{1 0 0} \mathbf{~ m l}$ & $\mathbf{g} / \mathbf{m}^{\mathbf{3}}$ & $\mathbf{g} / \mathbf{m}^{\mathbf{3} / \mathbf{s}}$ & Ton/Estação \\
\hline 1 & 5,4 & & 0,00000 & 0,0003 & 3,0000 & -- & -- \\
\hline 2 & 6,2 & 0,01228 & 0,07614 & 0,0013 & 13,0000 & 0,98977 & 7,70 \\
\hline 3 & 3,8 & 0,00675 & 0,02565 & 0,0008 & 8,0000 & 0,20520 & 1,59 \\
\hline 4 & 6,7 & 0,01469 & 0,09842 & 0,0001 & 1,0000 & 0,09842 & 0,77 \\
\hline 5 & 8,9 & 0,03330 & 0,29637 & 0,0048 & 48,0000 & 14,22576 & 110,62 \\
\hline 6 & 6,3 & 0,06958 & 0,43835 & 0,0002 & 2,0000 & 0,87671 & 6,82 \\
\hline 7 & 7,9 & 0,26744 & 2,11278 & 0,0008 & 8,0000 & 16,90221 & 131,43 \\
\hline 8 & 2,1 & 0,02127 & 0,04467 & 0,0024 & 24,0000 & 1,07201 & 8,34 \\
\hline 10 & 8,6 & 0,16760 & 1,44136 & 0,0081 & 81,0000 & 116,75016 & 907,85 \\
\hline 11 & 8,4 & 0,11823 & 0,99313 & 0,0002 & 2,0000 & 1,98626 & 15,45 \\
\hline TOTAL & 5,5 & -- & -- & 0,0004 & 4,0000 & -- & -- \\
\hline
\end{tabular}

Já na primavera, pode-se perceber o aumento significativo da vazão e do transporte fluvial, devido principalmente à desagregação e ressecamento do solo, a vegetação seca e desfolhada do cerrado, ocorrido durante o inverno que, aliado às altas 
precipitações durante esse período, $458,5 \mathrm{~mm}$, acaba carreando os sedimentos soltos para o canal fluvial, Tabela 6 e Figura 3.

Nesta estação, o ponto 9, a jusante da foz do córrego Buriti, localizada à jusante do Córrego Buriti, registrou o maior transporte de sedimentos em suspensão. Também devido ao bebedouro de gado e o uso, para a pecuária, sem curvas de nível e por receber vazão de águas freáticas do córrego Buriti, pois sua foz é marcada por "brejo", solo hidromórfico, que mesmo com mata ciliar preservada, promove a turbidez da água, por decomposição da matéria orgânica, Tabela 6.

Tabela 7: Mensurações de velocidade, área e de transporte de sedimentos fluviais em suspensão coletados no Verão de 2012, no córrego Moeda, Três Lagoas/MS.

\section{VERĀO de 2012}

\begin{tabular}{c|c|c|c|c|c|c|c}
\hline \multirow{2}{*}{ Pontos } & Velocidade & Area & Vazão & \multicolumn{4}{|c}{ Competência Fluvial } \\
\cline { 5 - 7 } & $(\mathbf{m} / \mathbf{s})$ & $\left(\mathbf{m}^{2}\right)$ & $\left(\mathbf{m}^{3} \mathbf{s}\right)$ & $\mathbf{g} / \mathbf{1 0 0} \mathbf{~ m l}$ & $\mathbf{g} / \mathbf{m}^{\mathbf{3}}$ & $\mathbf{g} / \mathbf{m}^{\mathbf{3}} \mathbf{s}$ & Ton/Estação \\
\hline 1 & 0,02 & & 0,00000 & 0,0180 & 180,0000 & -- & -- \\
\hline 2 & 1,55 & 0,01228 & 0,01903 & 0,0005 & 5,0000 & 0,09517 & 0,74 \\
\hline 3 & 2,75 & 0,00675 & 0,01856 & 0,0021 & 21,0000 & 0,38981 & 3,03 \\
\hline 4 & 2,60 & 0,01469 & 0,03819 & 0,0009 & 9,0000 & 0,34375 & 2,67 \\
\hline 5 & 7,20 & 0,03330 & 0,23976 & 0,0003 & 3,0000 & 0,71928 & 5,59 \\
\hline 6 & 5,20 & 0,06958 & 0,36182 & 0,0001 & 1,0000 & 0,36182 & 2,82 \\
\hline 7 & 5,20 & 0,26744 & 1,39069 & 0,0009 & 9,0000 & 12,51619 & 97,32 \\
\hline 8 & 1,10 & 0,02127 & 0,02340 & 0,0016 & 16,0000 & 0,37435 & 2,91 \\
\hline 9 & 5,40 & 0,16760 & 0,90504 & 0,0001 & 1,0000 & 0,90504 & 7,04 \\
\hline 10 & 14,20 & 0,11823 & 1,67887 & 0,0002 & 2,0000 & 3,35773 & 26,11 \\
\hline 11 & 0,01 & -- & -- & 0,0002 & 2,0000 & -- & - \\
\hline TOTAL & 45,23 & 0,64156 & 4,31354 & 0,0249 & 249,0000 & 18,70132 & 148,23 \\
\hline
\end{tabular}

O verão de 2012 foi pouco chuvoso, com 216,01 $\mathrm{mm}$ a menos que a normal, para esta estação e consecutivamente houve diminuição da vazão e do transporte em suspensão. Em relação à primavera, pois o solo úmido da primavera promoveu a recuperação das folhas das copas e das interceptações das gotículas, reduzindo o escoamento pluvial e fluvial, e o aumento da infiltração, Tabela 7 e Figura 3. Novamente 
nesta estação o ponto 7, volta a ser o de maior transporte de sedimentos em suspensão pelo córrego Moeda, Tabela 7.

Pode-se perceber essa diferença significativa do transporte de sedimentos ao longo de todas as estações (Figura 3) e (FIGURA 4), mostrando a grande importância das precipitações no transporte de sedimentos em suspensão, no inicio das chuvas de primavera e a brusca redução no verão, quando apesar dos solos encharcados, as praticas de ocupação e manejo da terra reduz eficazmente a ação da água corrente.

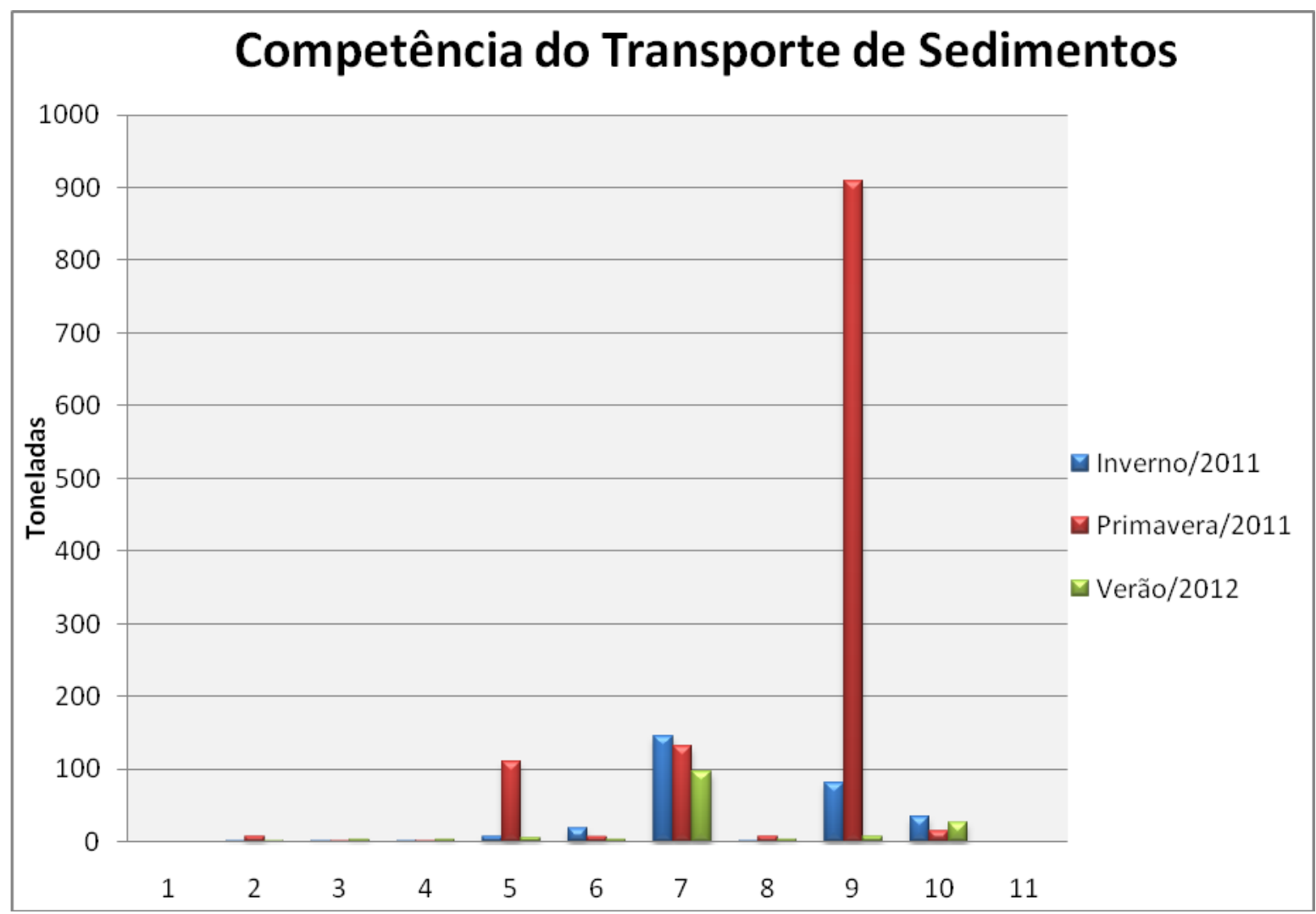

FIGURA 3: Competência do Transporte de Sedimentos em Suspensão em cada ponto durante o inverno e primavera de 2011 e verão de 2012, na bacia do córrego Moeda, Três Lagoas/MS.

Org: MEDEIROS, R. B. (2012).

Observamos uma diferença significativa na competência do transporte de sedimentos, no ponto 9 houve um grande aumento de sedimentos, ocasionados provavelmente por alguma atividade próxima ao local, derrubando sedimentos no córrego, fazendo com que o mesmo seja transportado pela água, ocasionando esse aumento significativo em relação à todos os outros pontos e todas as estações do ano. 


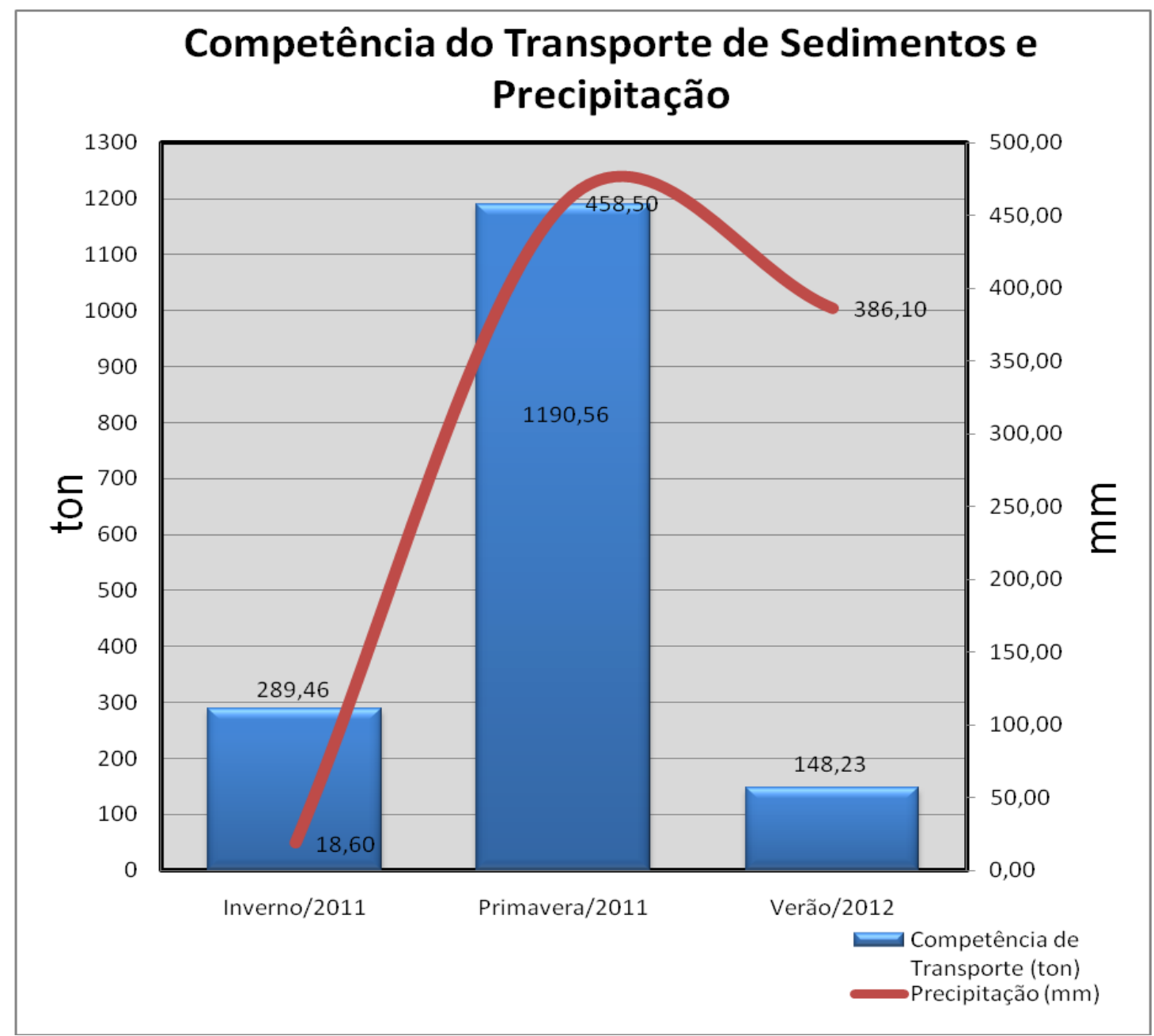

FIGURA 4: Competência Fluvial de Sedimentos em Suspensão Total, nas estações de inverno e primavera de 2011 e verão de 2012, na bacia do córrego Moeda, Três Lagoas/MS.

Org: MEDEIROS, R. B. (2012).

A diferença das precipitações entre a primavera e o verão, é de apenas $72,4 \mathrm{~mm}$, porém a diferença de transporte de materiais em suspensão pelo córrego Moeda, nestas estações foi elevadíssima, de 1.042,33 toneladas.

\section{CONCLUSÕES}




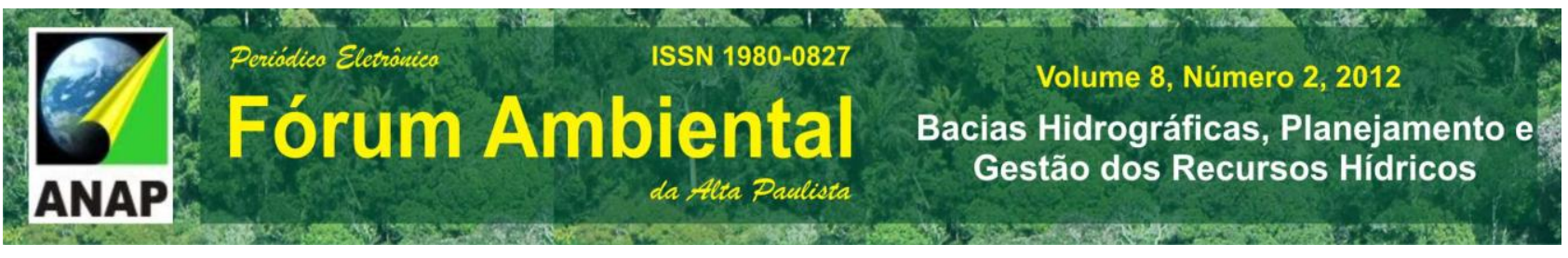

A concentração das precipitações proporciona maior potencial erosivo e consecutivo aumento de transporte de sedimentos em suspensão ao longo do canal fluvial. Contudo, mesmo no inverno seco de 2011, a vazão de estiagem não foi muito reduzida, em relação às do verão de 2012, devido à contribuição das águas subterrâneas, os solos ressequidos e desagregados foram mais transportados para o córrego, do que no verão. No verão os cerrados que emolduram as matas ciliares, estão verdes, com suas copas protegendo mais o solo, como também estes se encontram mais saturados de águas, possibilitando que as raízes auxiliem na maior infiltração.

No inverno, em todos os pontos monitorados 289,46 toneladas enquanto no verão, houve uma redução de transporte para 148,23 toneladas, já durante a primavera houve um aumento considerável, chegando a 1.190,56 toneladas, mostrando assim a questão do ressecamento do solo durante o inverno e esse solo solto sendo levado durante a primavera, onde começa a estação das chuvas.

O manejo correto dos hortos de eucalipto que recobrem boa parte da bacia e a preservação das matas ciliares e das reservas legais de cerrado. Os pontos 9 e 7 têm a sua margem esquerda com sua mata ciliar preservada e sua vertente ocupada com os hortos do Buriti e Granada e do lado direto, totalmente desmatado, recoberto por pastagens, sem curva de nível e não descompactado, obtendo em relação a todas as estações e pontos monitorados o maior transporte de sedimentos em suspensão na bacia.

Concluindo que na bacia do córrego Moeda, o plantio de eucalipto, além de facilitar a infiltração, protegendo mais o solo contra a ação das águas pluviais, proporciona maior regulação das vazões e redução do transporte de sedimentos em suspensão, do que as áreas ocupadas com pastagens. Constituindo o uso mais sustentável para a bacia, a única observação é que no período analisado as plantações com em média 3 anos de idade, estavam em ponto de corte. O grande problema seria se toda a bacia recoberta por eucalipto tivesse o corte no mesmo período, por essa razão, cada horto é plantado com em media um ano de diferença, para sempre terem boa parte da bacia com vegetação que proteja o solo. 


\section{REFERÊNCIAS}

BERTONI, J.; LOMBARDI NETO, F. Conservação do solo. 4ª edição. São Paulo: Ícone, 1999.

BERTONI, J.; LOMBARDI NETO, Francisco. Conservação do solo. São Paulo - SP. Ícone, 1990, 355p.

CASSETI, V. Elementos de Geomorfologia. Goiânia: Editora de UFG, 1994.

CHRISTOFOLLETTI, Antônio. Geomorfologia. São Paulo, Edgard Blücher, 2a edição, 1980.

Geomorfologia fluvial. São Paulo: Edgard Bluncher, 1981

CUNHA, C. M. L. Quantificação e mapeamento das perdas de solo por erosão com base na malha fundiária. Rio Claro: Instituto de Geociências e Ciências Exatas, UNESP, 1997.

DAVIDSON, J. "Ecological aspects of eucalyptus plantation". Proceedings Regional Expert Consultation on Eucalyptus, v. I, 4-8, oct. 1993.

ESPÍNDOLA, E.L.G. et. al. - A Bacia Hidrográfica do Córrego Monjolinho. RIMA. USP -Escola de Engenharia de São Carlos. São Carlos, 2000. IPEF Fibra. Jornal da Cenibra. Espírito Santo., n. 217, nov. 2003: 123 p..

LAL, R. Erodibility and erosivity. In: LAL, R. et al. Soil erosion research methods. Soil and Water Conservation Society. Washington, 1988. p. 141-160.

LOMBARDI NETO, F. e MOLDENHAUER, W,C. Erosividade da chuva - sua distribuição e relação com perdas de solo em Campinas, SP. Encontro Nacional de Pesquisas sobre conservação do Solo. 51, n.2, Campinas, 1992. Anais..., Campinas, Sociedade Brasileira de Ciência do Solo, 1992. p. 189-196.

PINTO, A. L.; A importância do Ribeirão Claro para o Abastecimento de água da cidade de Rio Claro-SP. Geografia Teorética. Rio Claro, v. 15, 1985: p. 104-117.

PINTO, André L.; LORENZ SILVA, J. L.; FERREIRA, A. G.; BASSO, P. M. Subsidio Geológico/Geomorfológico ao ordenamento do uso, ocupação e manejo do solo, visando à redução da perda de solo e a recuperação da qualidade das águas superficiais da Bacia do Córrego Bom Jardim, Brasilândia/MS. Relatório Parcial FUNDECT/MS. UFMS. Três Lagoas, 2009: 42p. 
ROCHA, O; PIRES, J. S. R.; SANTOS, J.E. Dos. A bacia hidrográfica como unidade de estudo e planejamento. In: A bacia hidrográfica do rio Monjolinho: Uma abordagem Ecossistêmica e a visão interdisciplinar. São Paulo: RIMA, 2000. p.1-16.

POORE, M. E. D; FRIES, C. The ecological effects of eucalyptus. FAO, 1985.

TUCCI, Carlos E. M. Hidrologia: Ciência e Aplicação. Porto Alegre: ed. Universidade/UFRGS: ABRH, 2000. 943 Pág.

VILELA FILHO, L. R. Estimativa da perda de solos em uma bacia hidrográfica sob o cultivo de frutíferas, no município de Valinhos (SP). 2002. $153 \mathrm{f}$. Trabalho de Conclusão de Curso (Geografia) - Instituto de Geociências, Universidade Estadual de Campinas, Campinas, SP, 2002.

VITAL, M. S. H. F. Impacto Ambiental de Florestas de Eucalipto Revista do BNDES. Rio de Janeiro, V. 14, N. 28, dez. 2007: p. 235-276. 